\title{
Analisis Efisiensi Teknis Penggunaan Pupuk dan Pestisida Budidaya Asparagus di Desa Pelaga, Kecamatan Petang, Kabupaten Badung
}

\author{
NUR RANGGA SIDHARTA, I MADE SUDARMA, \\ A.A.A WULANDIRA SAWITRI DJELANTIK \\ Program Studi Agribisnis, Fakultas Pertanian, Universitas Udayana \\ J1. PB. Sudirman Denpasar 80323 \\ Email: rangga.cro.gpb@gmail.com \\ sudarmaimade@yahoo.com
}

\begin{abstract}
Analysis of Technical Efficient Use of Fertilizer and Pesticide Cultivation Asparagus di Desa Pelaga, Kecamatan Petang, Kabupaten Badung
\end{abstract}

Pelaga Village located at the Subdistrict of Petang, Badung Regency is an area that carry out the program of One Village One Product (OVOP) with asparagus distinctive product since 2010. Cultivation of asparagus is influenced by the use of fertilizers and pesticides including chicken manure, cow manure, urea, NPK and pesticides, where the quantity of fertilizer and pesticide use affects the production of asparagus. This research aimed to analyze the effects of the use of fertilizers and pesticides, the farmer acceptance and to analyze the technical efficiency of cultivation of asparagus. This research uses multiple linear regression method that includes: classic assumption test consisting of normality test, heteroscedasticity, test of multicoliniearity and test the linear regression model, which includes: coefficient test determination (R2), F-test and t-test with a level real $(\alpha)$ of $5 \%$. After that, in order to analyze the technical efficiency by using the Data of Envelopment Analysis (DEA). The equation used is the production function model of Cobb-Douglas production function of the natural logarithm. The use of fertilizers and pesticides together in the cultivation of asparagus significantly affected the production of asparagus. Partially only cow manure (X2) and NPK (X4) which significantly affected the production of asparagus, asparagus farmers' income was Rp. 3,219,932 for a month and already exceeds the Minimum Wage of Badung Regency. Based on the analysis of technical efficiency, the asparagus cultivation has been efficient but has not been able to achieve performance levels of efficiency of full-technically efficient, because the average technical efficiency achieved was $63 \%$, with a range between $38.5 \%$ and $100 \%$. The value of technical inefficiency or technically inefficient average is $37 \%$.

Keywords: asparagus, efficiency, fertilizers, pesticides, production 


\section{Pendahuluan}

\subsection{Latar belakang}

Indonesia memerlukan sebuah strategi untuk mempertahankan dan meningkatkan kinerja dalam sektor pertanian sekaligus memperkecil ketertinggalan sektor pertanian dengan sektor lainnya. Salah satunya dengan menetapkan prioritas pengembangan komoditas pertanian unggulan, yaitu komoditas pertanian yang memiliki potensi untuk dikembangkakan, memiliki prospek untuk diserap pasar lokal, nasional maupun internasional, dan memiliki nilai tambah tinggi (high value crop) yang salah satunya adalah tanaman asparagus Asparagus adalah tanaman subtropis yang diambil rebungnya untuk dikonsumsi (Susetyo,2015).

Desa Pelaga, Kecamatan Petang, Kabupaten Badung adalah daerah yang mengusung program One Village One Product (OVOP) dengan produk unggulan asparagus sejak tahun 2010. Program (OVOP) di Desa Pelaga diawali oleh Kemenetrian Koperasi dan UKM yang bekerja sama dengan konsultan dari Taiwan International Cooperation Development Fund (ICDF). Koperasi Mertanadi adalah koperasi yang berada di Banjar Bukian Desa Pelaga, Kecamatan Petang. Hingga saat ini petani yang anggotanya menanam asparagus di Desa Pelaga berjumlah 60 orang.

Berdasarkan uraian diatas penelitian penggunaan pupuk dan pestisida unsur faktor yang sulit menentukan dalam produktivitas asparagus penting dilakukan untuk menilai effisiensi penggunaan pupuk dan pestisida karena secara teknis budidaya asparagus memegang peranan penting dalam berusahatani. Penggunaan pupuk dan pestisida secara efektif dan efisien membantu petani dalam mengalokasikan biaya usahatani secara tepat untuk mendapatkan keuntungan maksimum (Soekartawi, 2002).

\subsection{Tujuan Penelitian}

Berdasarkan permasalahan yang telah dikemukakan di atas, maka penelitian ini memiliki tujuan sebagai berikut:

1. Untuk mengetahui jenis pupuk dan pestisida yang berpengaruhterhadap produksi asparagus di kelompok Koperasi Tani Mertanadi, Desa Pelaga, Kecamatan Petang,Kabupaten Badung.

2. Untuk mengetahui besarnya penerimaan petani asparagus di kelompok Koperasi Tani Merta Nadi, Desa Pelaga, Kecamatan Petang, Kabupaten Badung.

3. Untuk mengetahui efisiensi teknis penggunaan pupuk dan pestisida dalam budidaya asparagus di kelompok Koperasi Tani Mertanadi, Desa Pelaga, Kecamatan Petang,Kabupaten Badung.

\section{Metodelogi Penelitian}

\subsection{Lokasi dan Waktu Penelitian}

Penelitian ini dilaksanakan di Desa Pelaga, Kecamatan Petang, Kabupaten Badung dari bulan April sampai dengan Agustus 2016. 


\subsection{Populasi dan Sampel}

Populasi dalam penelitian ini yaitu petani asparagus yang terdaftar dalam anggota Koperasi Mertanadi sebanyak 60 petani. Jumlah sampel dalam penelitian ini sebanyak 38 orang yang ditentukan dengan menerapkan rumus slovin (Sevilla dalam Suryana, 2007).

$$
\mathrm{n}=\frac{\mathrm{N}}{1+\mathrm{Ne}^{2}}
$$

Keterangan:

$\mathrm{n} \quad=$ Jumlah sampel

$\mathrm{N}=$ Jumlah populasi

e $=$ Batas toleransi kesalahan $(10 \%)$

Teknik pengambilan sampel mempergunakan metode accidental samplingyang berarti pengambilan sampel dari populasi tidak memiliki kesempatan yang sama untuk dipilih menjadi anggota sampel dan mereka (petani) kebetulan muncul di lokasi penelitian (Sugiyono, 2001:62).

\subsection{Jenis dan Sumber Data}

Data kuantitatif dalam penelitian ini meliputi data karakteristik petani yang terdiri dari luas garapan petani, usia petani,dan lama pendidikan formal petani. jumlah penggunaan dan harga faktor produksi yang terdiri dari pupuk kandang sapi, kandang ayam, pupuk Urea, pupuk NPK, pestisida, dan data produksi petani asparagus di dalam kelompok Koperasi Tani Merta Nadi. Data kualitatif dalam penelitian ini meliputi karakteristik status kepemilikan lahan petani, data gambaran umum lokasi penelitian, dan struktur organisasi di Koperasi Tani Mertanadi.

Berdasarkan sumber yang digunakan dalam penelitian ini meliputi data primer yang terdiri dari data karakteristik petani, data penggunaan dan harga faktor produksi, data produksi, dan harga jual asparagus di lokasi penelitian. Data sekunder meliputi data hasil produksi asparagus dari Koperasi Mertanadi di lokasi penelitian.

\subsection{Metode Pengumpulan Data}

Metode pengumpulan data dalam penelitian ini sebagai berikut.

1. Library research, yaitu penelitian yang dilakukan dengan cara membaca berbagai sumber literatur atau kajian pustaka yang berkaitan dengan penelitian yang dilakukan.

2. Field research, ialah cara pengumpulan data yang diperoleh secara langsung dari lapangan. Adapun metode yang diterapkan meliputi pengamatan (observation), wawancara (interview), dan dokumentasi.

\subsection{Metode Analisis Data}

Data dalam penelitian ini dijelaskan secara deskriptif kuantitatif, dianalisis menggunakan aplikasi komputer IBM SPSS Statistic Version 21. DEAP 2.1 
danMicrosoft Excel 2007, serta dikaji dengan menerapkan beberapa metode sebagai berikut.

\subsubsection{Pengujian regresi linier berganda}

Fungsi produksi usahatani asparagus telah dispesifikasi dan diestimasi dengan fungsi produksi Cobb-Douglass sehingga dapat didefinisikan sebagai berikut.

$$
\mathrm{Y}=\mathrm{a} \mathrm{X}{ }_{1}^{\mathrm{b} 1} \mathrm{X}_{2}{ }^{\mathrm{b} 2} \ldots \ldots \ldots \ldots . . . . \mathrm{X}_{\mathrm{i}}^{\mathrm{bi}} \ldots \ldots \ldots \mathrm{X}_{\mathrm{n}}{ }^{\mathrm{bn}} \mathrm{e}^{\mathrm{u}} \text {. }
$$

Keterangan:

$\mathrm{Y} \quad=$ Produksi asparagus (Kilogram/are)

$\mathrm{X}=$ pupuk kandang ayam, pupuk kandang sapi, pupuk urea, pupuk NPK, dan pestisida

$\mathrm{a}, \mathrm{b}=$ Besaran yang akan diduga

$\mathrm{u} \quad=$ Kesalahan (disturbance term)

$\mathrm{e} \quad=$ Logaritma natural $(\mathrm{e}=2,718)$

Fungsi tersebut dispesifikasi dan di estimasi ke fungsi linier dalam bentuk logaritma natural dan dilakukan pengujian untuk memenuhi kriteria ekonometrika dengan uji asumsi klasik yang meliputi uji normalitas, multikolinearitas, heterokedasitas dan kriteria statistika yang meliputi uji koefisien determinasi, uji $\mathrm{F}$, dan uji t pada taraf nyata 0,05. Data dianalisis dalam bentuk logaritma natural agar tidak terjadi penyimpangan dalam uji asumsi klasik (Santosa, 2005).

\subsubsection{Efesiensi Teknis}

Efisiensi teknis adalah perbandingan antara produksi aktual dengan tingkat produksi yang potensial dapat dicapai (Soekartawi, 2001). Untuk mengetahui tingkat efisiensi teknis (TechnicalEficiency Rate) dapat dilakukan pendekatan dengan ratio varians, yakni

$$
\gamma=\left(\sigma_{v}^{2}\right) /\left(\sigma^{2}\right)
$$

dimana

$$
\sigma=\sigma_{v}^{2}+\sigma_{v}^{2} \text { dan } 0 \leq \gamma \leq 1
$$

Apabila $\gamma$ mendekati 1 , dan $2 \sigma$ mendekati nol dan tingkat vi adalah tingkat kesalahan maka dikatakan in-efisiensi. Perbedaan antara output aktual dan output potensial menunjukkan in-efisiensi dalam produksi.

Efisiensi teknik menurut Soekartawi (2001) dapat dihitung dengan rumus :

$$
E T=Y i-Y i i
$$

$\mathrm{ET}=$ Tingkat efisiensi teknis

Yi = Besarnya produksi (output) ke-i

Yii = Besarnya produksi yang diduga pada pengamatan ke-i yang diperoleh melalui fungsi produksi frontier Cobb-Douglas.

Pengukuran efisiensi yang diukur dengan menggunakan analisis DataEnvelopment Analysis (DEA) memiliki karakter yang berbeda dengan konsepefisiensi pada umumnya. Pertama, efisiensi yang diukur bersifat teknis, bukan 
alokatif atau ekonomis. Analisis DEA hanya memperhitungkan nilai absolute dari suatu variabel. Oleh karenanya dimungkinkan suatu polaperhitungan kombinasi berbagai variabel dengan satuan yang berbeda-beda. Kedua, nilai efisiensi yang dihasilkan bersifat relatif atau hanya berlaku dalam lingkup petani asparagus yang menjadi Unit Kegiatan Ekonomi (UKE) yang diperbandingkan tersebut.Formulasi dengan menggunakan DEA, misalnya dilakukan perbandingan efisiensi dari sejumlah UKE, pada penelitian ini UKE adalah lahan petani asparagus yang menghasilkan rebung asparagus. Setiap UKE menghasilkan $\mathrm{m}$ jenis input untuk menghasilkan $\mathrm{s}$ jenis output. Misalnya Xij $>0$ merupakan jumlah input yang digunakan oleh UKE $\mathrm{j}$, dan misalnya Yij $>0$ merupakan jumlah output $\mathrm{r}$ yang dihasilkan oleh UKE $\mathrm{j}$.

Variabel keputusan (decision variable) dari kasus tersebut adalah bobot yang harus diberikan pada setiap unit input dan output oleh UKE $\mathrm{k}$. $\mathrm{V}_{\mathrm{ik}}$ adalah bobot yang diberikan pada unit $\mathrm{I}$ oleh kegiatan $\mathrm{k}$ dan $\mathrm{U}_{\mathrm{rk}}$ merupakan variabel keputusan, yakni variabel yang nilainya akan ditentukan melalui program linear fraksional, satu formulasi program linear untuk setiap UKE dalam sampel. Fungsi tujuan (objective function) dari setiap linear program fraksional tersebut adalah rasio dari output tertimbang total (total weighted output) dari UKE k dibagi dengan input tertimbang totalnya (Dendawijaya, 2001). Formulasi fungsi tujuan tersebut adalah :

Maksimumkan :

$$
\mathrm{Z}_{\mathrm{k}}=\frac{\sum_{\mathrm{r}}^{\mathrm{s}}=1 \mathrm{U}_{\mathrm{rk}} \mathrm{Y}_{\mathrm{rk}}}{\sum_{\mathrm{i}}^{\mathrm{m}}=1 \mathrm{~V}_{\mathrm{ik}} \mathrm{X}_{\mathrm{ik}}}
$$

$\mathrm{Z}_{\mathrm{k}} \quad$ : adalah efisiensi teknis budidaya asparagus

Setiap unit kegiatan ekonomi, dimana dalam penelitian ini merupakan budidaya asparagus, menggunakan lima jenis input produksi, yakni ; pupuk kandang ayam, pupuk kandang sapi, pupuk NPK, pupuk urea, dan pestisida, serta menghasilkan satu jenis output yakni asparagus.Kriteria universalitas mensyaratkan unit kegiatan ekonomi k untuk memiliki bobot dengan batasan atau kendala bahwa tidak ada satu unit kegiatan ekonomi lain yang akan memiliki efisiensi lebih besar 1 atau $100 \%$, jika unit kegiatan ekonomi lain tersebut menggunakan bobot yang dipilih oleh unit kegiatan ekonomi k sehingga formulasi selanjutnya adalah :

$$
\frac{\sum_{r}^{s}=1 U_{r k} Y_{r k}}{\sum_{i}^{m}=1 V_{i k} X_{i k}} \leq i, i=1 \ldots, n
$$

Urk $\geq 0 ; r=1, \ldots \ldots \ldots \ldots . . . s$

Vik $\geq 0 ; r=1, \ldots \ldots \ldots \ldots . . . m$

Dimana n, menunjukkan jumlah sampel. Objek dalam penelitian ini berjumlah 38 sampel. Pertidaksamaan pertama menunjukkan adanya efisiensi rasio untuk UKE lain tidak lebih dari 1, sementara persamaan kedua berbobot positif. Angka rasio akan bervariasi antara 0 sampai dengan 1. Objek penelitian dikatakan efisien apabila memiliki angka rasio mendekati $100 \%$, sebaliknya jika mendekati 0 
menunjukkan efisiensi objek yang semakin rendah. Beberapa bagian program linier ditransformasikan ke dalam program ordinary linier sebagai berikut :

$$
\frac{\sum_{r}^{s}=1 U_{r k} Y_{r k}}{\sum_{i}^{m}=1 V_{i k} X_{i k}} \leq i, i=1 \ldots, n
$$

Urk $\geq 0 ; \mathrm{r}=1, \ldots \ldots \ldots \ldots . . \mathrm{s}$

Vik $\geq 0 ; r=1, \ldots \ldots \ldots \ldots \ldots m$

Program linier fraksional kemudian ditransformasikan ke dalam linier biasa (ordinary linier program) dan metode simpleks untuk menyelesaikannya.

\subsubsection{Penerimaan}

Penerimaan usahatani adalah perkalian antara produksi yang diperoleh dengan harga jual (Rahim dan Hastuti, 2007). Secara matematis dirumuskan sebagai berikut :

$$
\mathrm{TR}=\mathrm{Y} . \mathrm{P}
$$

Keterangan :

TR : Penerimaan

Y: Produksi

P: Harga jual

\section{Hasil dan Pembahasan}

\subsection{Karakteristik Petani asparagus di Desa Pelaga}

Karakteristik Petani asparagus di Desa Pelagasecara rinci dapat dilihat pada Tabel 1. berikut ini.

Tabel 1.

Karakteristik Petani Asparagus di Desa Pelaga

\begin{tabular}{lcc}
\hline Uraian Karakteristik Petani & Nilai Karakteristik & Rata-rata \\
\hline Luas lahan garapan (Hektar) & $>0,5$ s.d. 0,5 & 24,9 \\
Usia petani (Tahun) & 15 s.d.64 & 38,0 \\
Pengalaman berusahatani (Tahun) & 5 s.d.40 & 21,4 \\
Lama Pendidikan formal (Tahun) & 6 s.d. 16 & 12,7 \\
\hline
\end{tabular}

Sumber: Data primer (diolah), 2016.

Tabel 1 menunjukkan luas garapan petani tergolong sempit karena rata-rata luas lahan garapan yang kurang dari 0,5 hektar. Petani asparagus di Desa Pelaga tergolong ke dalam usia produktif karena rata-rata usia petani yang kurang dari 64 tahun dan hal ini menunjukkan petani dapat bekerja dengan baik dan maksimal dalam berusahatani asparagus. Rata-rata pengalaman petani berusahatani asparagus selama 27 tahun dan hal ini menunjukkan bahwa petani mudah dalam menerapkan inovasi dan teknologi yang dianjurkan oleh penyuluh pertanian. Rata-rata lama pendidikan formal Petani asparagus di Desa Pelaga selama 12 tahun dan hal ini menunjukkan bahwa petani lebih cepat dalam menerapkan teknologi baru serta 
menerima inovasi dari penyuluh pertanian karena pendidikan petani sudah melebihi anjuran pemerintah yaitu wajib belajar sembilan tahun.

\subsection{Analisis Pengaruh Faktor Produksi Terhadap Produksi Asparagus}

Persamaan fungsi produksi diuji untuk memenuhi kriteria ekonometrika yang meliputi uji normalitas, heterokedasitas, multikolinearitas, dan kriteria statistika yang meliputi uji koefisien determinasi $\left(\mathrm{R}^{2}\right)$, uji $\mathrm{F}$, dan uji t. Adapun persamaan fungsi produksi yang diuji dalam bentuk linier yaitu $\operatorname{LnY}=\beta_{0}+\beta_{1} \operatorname{Ln} X_{1}+\beta_{2} \operatorname{Ln} X_{2}+\beta_{3} \operatorname{LnX} 3$ $+\beta_{4} \operatorname{LnX}_{4}+\beta_{5} \operatorname{LnX} 5$

1. Uji kriteria ekonometrika dengan uji asumsi klasik

Uji normalitas pada Gambar 1. menunjukkan bahwa nilai plot PP pada grafik Normal P-P Plot of Regression Standardizen residual terletak di sekitar garis diagonal yang berarti data berdistribusi secara normal.

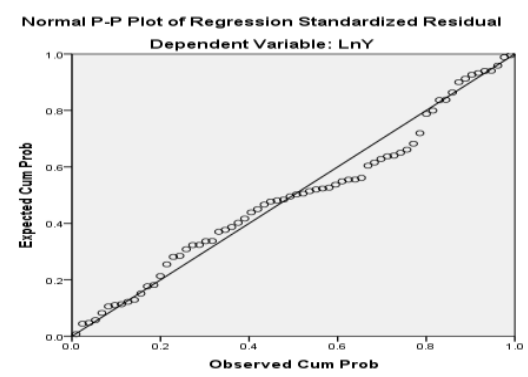

Gambar 1. Hasil Uji Normalitas

Uji multikolinearitas menunjukkan bahwa seluruh faktor produksi memiliki nilai VIF kurang dari 10 dan tolerance lebih dari 0,1 yang berarti tidak ada gejala multikolinearitas. Hasil analisis dapat dilihat pada Tabel 2. berikut ini

Tabel 2.

Hasil Uji Multikolinearitas

\begin{tabular}{lcc}
\hline \multicolumn{1}{c}{ Variabel } & Nilai Tolerance & Nilai VIF \\
\hline Pupuk kandang ayam & 0,454 & 2,203 \\
Pupuk Kandang sapi & 0,794 & 1,259 \\
Pupuk Urea & 0,546 & 1,830 \\
Pupuk NPK & 0,516 & 1,937 \\
Pestisida & 0,736 & 1,359 \\
\hline
\end{tabular}

Sumber: Data primer (diolah), 2016.

Uji heteroskedasitas pada Gambar 2. menunjukkan penyebaran dari varians residual yang terdapat pada grafik scatterplot, varians residual terpencar dan tidak membentuk pola tertentu yang berarti tidak adanya gejala homokedastitas. 


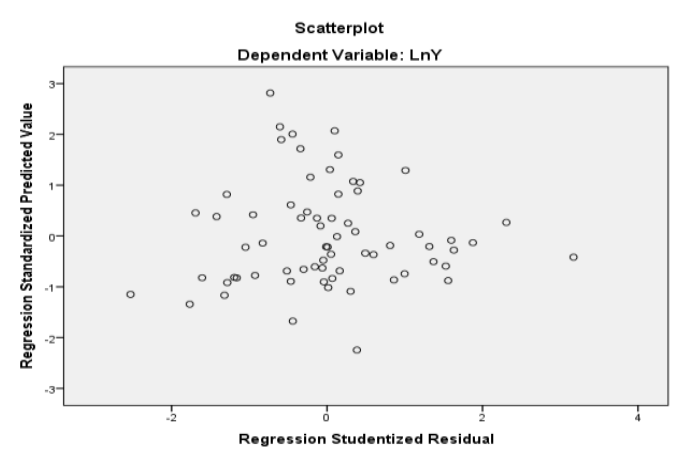

Gambar 2. Hasil Uji Heteroskedasitas

2. Uji kriteria statistika dengan uji $\mathrm{R}^{2}$, uji $\mathrm{F}$, dan uji $\mathrm{t}$

Nilai $R$ square pada uji koefisien determinasi $\left(\mathrm{R}^{2}\right)$ yaitu 0,443 yang memiliki arti $44,3 \%$ nilai variasi keragaman total hasil produksi asparagus yang dapat diterangkan oleh faktor produksi dan sisanya 55,7\% dapat diterangkan oleh faktor produksi lainnya yang tidak termasuk di dalam analisis. Nilai significance $\mathrm{F}$ dalam hasil uji $\mathrm{F}$ yaitu 0,03 yang memiliki arti secara simultan atau bersama-sama, seluruh faktor produksi berpengaruh positif terhadap hasil produksi asparagus. Apabila petani menambah atau mengurangi jumlah seluruh penggunaan faktor produksi maka akan mempengaruhi hasil produksi. Fungsi produksi Cobb-Douglass telah dispesifikasi dan diestimasi ke bentuk linier dalam logaritma natural menjadi LnY = 7.410- 0,003 $\operatorname{LnX}_{1}+0,021 \operatorname{LnX}_{2}+0,246 \operatorname{LnX}_{3}+0,775 \operatorname{LnX}_{4}-3,579 \operatorname{LnX} 5$

Tabel 3.

Hasil Uji t Model Fungsi Produksi Cobb-Douglass

\begin{tabular}{lcccc}
\hline \multicolumn{1}{c}{ Variabel } & Bi & Nilai t-hitung & Sig. & Keterangan \\
\hline Konstanta & 27,358 & 0,336 & 0,739 & Tidak Nyata \\
Pupuk kandang ayam & $-0,001$ & $-0,241$ & 0,811 & Tidak Nyata \\
Pupuk kandang sapi & 0,017 & 2,445 & 0,020 & Nyata \\
Pupuk urea & 0,346 & 0,781 & 0,441 & Tidak Nyata \\
Pupuk NPK & 0,558 & 2,087 & 0,045 & Nyata \\
Pestisida & $-2,739$ & $-0,445$ & 0,659 & Tidak Nyata \\
\hline
\end{tabular}

Sumber: Data primer (diolah), 2016.

Nilai significance uji t faktor produksi pada Tabel 3. menunjukkan bahwa secara parsial atau individu faktor produksi yang meliputi pupuk kandang sapi, dan pupuk NPK, berpengaruh positif terhadap produksi asparagus. Apabila petani menambah atau mengurangi jumlah salah satu faktor produksi maka akan mempengaruhi hasil produksi.

\subsection{Penerimaan}

Berdasarkan tabulasi data diperoleh hasil penerimaan rata-rata petani asparagus di desa plaga adalah sebesarRp. 3.219.932selama sebulan. Berdasarkan 
data yang diperoleh dari Disnaker mengenai Peraturan Gubernur Bali tanggal 4 Januari 2016 nomor 1 tahun 2015 tentang upah minimum Kabupaten / Kota bahwa upah minimum regional badung adalah sebesar RP 2.124.075. dapat kita ketahui bahwa penerimaan petani asparagus di desa Pelaga sudah melebihi UMR Kota Badung. Jadi dalam hal ini sebaiknya petani tetap melakukan usahataninya walaupun dalam kondisi yang belum optimal karena apabila berhenti menjadi petani dan memilih bekerja disektor lain tentunya penerimaan yang diterima lebih rendah.

\subsection{Effisiensi teknis}

Pengukuran efisiensi menggunakan Data Envelopment Analysis (DEA) menunjukkan bahwa budidaya asparagus di Desa Pelaga belum mampu mencapai performansi tingkat efisiensi yang full-efisien secara teknis, karena rata-rata efisiensi teknis yang dicapai sebesar 63\%, dengan kisaran antara 38,5\% hingga $100 \%$. Nilai inefisiensi teknis rata-rata adalah sebesar $37 \%$. Hal ini mengindikasikan masih adanya peluang bagi petani asparagus untuk untuk meningkatkan hasil produksinya dengan mengoptimalkan penggunaan pupuk dan pestisida secara efisien untuk mendapatkan output yang optimum. Petani asparagus di Desa Pelaga sebesar 21\% beroperasi pada skala CRS (Constant Return to Scale), sedangkan 7\% beroperasi pada skala DRS (Decreasing Return to Scale), dan sebesar 79\% UKE efisien dan 93\% UKE tidak efisien beroperasi pada skala IRS (Increasing Return to Scale) yang artinya setiap penambahan input terjadi peningkatan terhadap output. Agar petani yang beroperasi pada skala DRS dapat beroperasi secara optimal (CRS), maka petani dapat melakukan minimalisasi penggunaan input.

\section{Simpulan dan Saran}

\subsection{Simpulan}

Berdasarkan hasil analisis dan pembahasan yang telah dilakukan, kesimpulan dalam penelitian ini sebagai berikut.

1. Kesimpulan penelitian ini yaitu secara simultan penggunaan pupuk dan pestisida yang meliputi untuk penggunaan pupuk kandang ayam $\left(\mathrm{X}_{1}\right)$, penggunaan pupuk kandang sapi $\left(\mathrm{X}_{2}\right)$, penggunaan pupuk urea $\left(\mathrm{X}_{3}\right)$, penggunaan pupuk NPK $\left(\mathrm{X}_{4}\right)$, dan penggunaan pestisida $\left(\mathrm{X}_{5}\right)$ secara bersamasama mempengaruhi produksi asparagus di Desa Pelaga, namun secara parsial hanya pupuk kandang sapi $\left(\mathrm{X}_{2}\right)$ dan pupuk NPK $\left(\mathrm{X}_{4}\right)$ berpengaruh positif terhadap produksi asparagus.

2. Penerimaan petani rata-rata sudah melebihi UMR kota Badung walaupun di dalam kegiatan usahataninya belum optimal dalam penggunaan input.

3. Secara teknis petani di Desa Pelaga sudah efisien di dalam penggunaan pupuk dan pestisida untuk memproduksi asparagus.

\subsection{Saran}

Berdasarkan hasil analisis dan pembahasan yang telah dilakukan, saran dalam penelitian ini sebagai berikut. 
1. Saran yang dapat diberikan dalam penelitian ini yaitu petani asparagus di Desa Pelaga harus lebih memperhatikan dalam penggunaan pupuk kandang sapi dan pupuk NPK karena berpengaruh positif terhadap produksi asparagus

2. Petani asparagus di Desa Pelaga yang belum efisien harus lebih berhati-hati dalam penggunaan pupuk dan pestisida dan dapat menyesuaikan penggunaan pupuk dan pestisida mereka dengan petani yang sudah efisien agar usahataninya bisa berjalan secara maksimal sehingga para petani asparagus tidak beralih ke tanaman lain dalam berusahatani.

3. Pemerintah perlu memberikan penyuluhan dan pengawasan kepada petani asparagus di desa plaga mengenai dosis yang tepat dalam penggunaan pupuk dan pestisida.

4. Bagi peneliti lain yang akan mengembangkan penelitian ini diharapkan kedepannya mampu menganalisis efisiensi alokatif, efisiensi harga, efisiensi ekonomis, dan dapat menambahkan faktor-faktor produksi lain yang berpengaruh terhadap produksi asparagus.

\section{Daftar Pustaka}

Dendawijaya, Lukman. 2001. Manajemen Perbankan. Ghalia Indonesia. Jakarta

Peraturan Gubernur Bali no 1 Tahun 2016 tentang upah minimum Kabupaten / Kota Tersedia: http://disnaker.baliprov.go.id/po-content/po-upload/umk-2015663401-popoji.pdf. Diakses tanggal 4 Desember 2016

Rahim. Abd. dan. Hastuti. DRW. 2007. Ekonomi Pertanian. Penebar Swadaya, Jakarta.

Santosa. Ashari. 2005. Analisis Statistik dengan Microsoft Excel \& SPSS. Penerbit Andi. Yogyakarta.

Sugiyono 2001, Metode Penelitian Administrasi, Penerbit Alfabeta. Bandung

Suryana, S. 2007. Analisis Faktor-faktor yang Mempengaruhi Produksi Jagung di Kabupaten Blora. Tesis Magister Ilmu Ekonomi dan Pembangunan Universitas Diponegoro. Tersedia online di: http://eprints.undip.ac.id. Diakses tanggal 19 Juli 2016.

Susetyo,Wawan. 2015. Sukses Bertanam Asparagus, Prospek Usaha Bagus (Edisi

Pertama). Pustaka Baru Press. Yogyakarta

Soekartawi. 2001. Analisis Usahatani. UI Press. Jakarta

Soekartawi, 2002. Prinsip Dasar Ekonomi Pertanian (Teori dan Aplikasi) Edisi Revisi. PT RajaGrafindo Persada. Jakarta.

Soekartawi. 2006. Analisis Usahatani. Universitas Indonesia Press. Jakarta. 